\title{
Comparison of predictive equations for resting energy expenditure among patients with schizophrenia in Japan
}

This article was published in the following Dove Press journal:

Neuropsychiatric Disease and Treatment

28 February 2014

Number of times this article has been viewed

\author{
Norio Sugawara' \\ Norio Yasui-Furukori' \\ Tetsu Tomita ${ }^{1,2}$ \\ Hanako Furukori ${ }^{3}$ \\ Kazutoshi Kubo ${ }^{1,4}$ \\ Taku Nakagami',4 \\ Sunao Kaneko' \\ 'Department of Neuropsychiatry, \\ Hirosaki University School of \\ Medicine, Hirosaki, ${ }^{2}$ Department of \\ Psychiatry, Hirosaki-Aiseikai Hospital, \\ Hirosaki, ${ }^{3}$ Department of Psychiatry, \\ Kuroishi-Akebono Hospital, Kuroishi, \\ ${ }^{4}$ Department of Psychiatry, Odate \\ Municipal General Hospital, Odate, \\ Japan
}

Background: Recently, a relationship between obesity and schizophrenia has been reported. The prediction of resting energy expenditure (REE) is important to determine the energy expenditure of patients with schizophrenia. However, there is a lack of research concerning the most accurate REE predictive equations among Asian patients with schizophrenia. The purpose of the study reported here was to compare the validity of four REE equations for patients with schizophrenia taking antipsychotics.

Methods: For this cross-sectional study, we recruited patients $(n=110)$ who had a Diagnostic and Statistical Manual of Mental Disorders, fourth edition, diagnosis of schizophrenia and were admitted to four psychiatric hospitals. The mean ( \pm standard deviation) age of these patients was $45.9 \pm 13.2$ years. Anthropometric measurements (of height, weight, body mass index) were taken at the beginning of the study. REE was measured using indirect calorimetry. Comparisons between the measured and estimated REEs from the four equations (Harris-Benedict, Mifflin-St Jeor, Food and Agriculture Organization/World Health Organization/United Nations University, and Schofield) were performed using simple linear regression analysis and Bland-Altman analysis.

Results: Significant trends were found between the measured and predicted REEs for all four equations $(P<0.001)$, with the Harris-Benedict equation demonstrating the strongest correlation in both men and women $(r=0.617, P<0.001)$. In all participants, Bland-Altman analysis revealed that the Harris-Benedict and Mifflin-St Jeor equations did not show a significant bias in the prediction of REE, however, a significant overestimation error was shown for the Food and Agriculture Organization/World Health Organization/United Nations University and Schofield equations.

Conclusion: When estimating REE in patients with schizophrenia taking antipsychotics, the Harris-Benedict equation appears to be the most appropriate for clinical use.

Keywords: indirect calorimetry, Japanese, Harris-Benedict equation, antipsychotics

\section{Introduction}

Weight gain among patients with schizophrenia is a growing concern because the prevalence of obesity among patients with schizophrenia is higher than the prevalence in the general population. ${ }^{1-3}$ Patients with schizophrenia are at risk for becoming obese due to antipsychotic drug use, ${ }^{4}$ poor dietary habits, ${ }^{5}$ and lack of exercise or limited activity due to the negative symptoms of the disease. ${ }^{6}$

Several studies have shown that being overweight is a major risk factor for metabolic syndrome, cardiovascular diseases, and premature death. ${ }^{7-9}$ Further, obesity is associated with increased medication costs ${ }^{10}$ noncompliance with antipsychotic medication
Department of Neuropsychiatry,

Hirosaki University School of Medicine,

5 Zaifucho, Hirosaki City, Aomori,

036-8562, Japan

$\mathrm{Tel}+8 \mid \mathbf{I} \mathbf{7 2} 395066$

Fax +8I I72395067

Email nsuga3@yahoo.co.jp 
regimens, ${ }^{11}$ poorer psychosocial adaptation, ${ }^{12}$ and reduced quality of life ${ }^{13}$ among patients with schizophrenia.

There are three principal components of energy expenditure (EE) in humans: 1) the resting energy expenditure (REE), 2) the thermic effects of food, and 3) the EE of physical activity. REE is the largest component of EE, ranging from $68 \%$ to $80 \%$ of non-activity total $\mathrm{EE},{ }^{14}$ and it is determined by several factors, including age $,{ }^{15} \mathrm{sex},{ }^{16}$ body weight, and fat-free mass. ${ }^{17}$ The maintenance of weight is the result of a balance between energy intake and expenditure. ${ }^{18}$

Previous studies among patients with severe mental illnesses (SMIs) have assessed the predictive equations for REE only in Western populations. ${ }^{19-21}$ The differences in lifestyle and physique make it difficult to extrapolate the predictive REE equations used in populations of European descent for use in Asian populations. Therefore, the purpose of the study reported here was to measure REE in a group of male and female patients with schizophrenia who were taking antipsychotic medication and to determine whether REE can be reliably estimated using previously published predictive equations.

\section{Methods}

\section{Participants}

This study was conducted between January and September 2012. The subjects included 110 outpatients (69 males and 41 females) at four psychiatric hospitals in Japan who were diagnosed with either schizophrenia or schizoaffective disorder based on Diagnostic and Statistical Manual of Mental Disorders, fourth edition, diagnostic criteria. ${ }^{22}$ The diagnoses of the patients were recorded from their medical charts. The data collection for this study was approved by the Ethics Committee of Hirosaki University School of Medicine, and all subjects provided written informed consent before participating in the study.

\section{Procedure}

Demographic (age and sex) and medication data were obtained from the participants' medical records. Of the 110 subjects in the study, 73 were receiving antipsychotic combination therapy and 37 were receiving antipsychotic monotherapy. Of the 37 patients receiving antipsychotic monotherapy, ten were taking high metabolic risk antipsychotics (olanzapine $=6$, quetiapine =4), 13 patients were taking risperidone, eleven patients were taking aripiprazole, two patients were taking blonanserin, and one patient was taking perospirone. Patient height was determined without shoes on a portable stadiometer with the mandible plane parallel to the floor.
The REE measurements were performed using a MedGem ${ }^{\mathrm{TM}}$ portable indirect calorimeter (HealtheTech, Inc., Golden, CO, USA) following an overnight fast and 30 minutes of rest at a constant temperature in a relaxing environment. Subjects were instructed to position the nose clips and try to breathe nasally to test that nasal respiration was blocked. The calorimeter used for this study was auto-calibrated for 5 minutes before testing. After the calibration was complete, the patients were instructed to place the single-use mouthpiece into their mouths and breathe normally. A typical reading took approximately 10 minutes to obtain.

\section{Predictive REE equations}

The predictive regression equations of Harris and Benedict, ${ }^{23}$ Mifflin et al (the Mifflin-St Jeor equation), ${ }^{24}$ the Food and Agriculture Organization/World Health Organization/United Nations University (FAO/WHO/UNU), ${ }^{25}$ and Schofield ${ }^{26}$ were used to calculate REE (Table 1).

Table I Equations used for the estimation of resting energy expenditure in $\mathrm{kcal} / \mathrm{day}$

\begin{tabular}{|c|c|}
\hline Name of equation & Equation \\
\hline \multicolumn{2}{|l|}{ Harris-Benedict ${ }^{23}$} \\
\hline Male & $\begin{array}{l}66.0+13.7 \times \text { weight }(\mathrm{kg})+5.0 \times \text { height }(\mathrm{cm})- \\
6.8 \times \text { age }(\text { year })\end{array}$ \\
\hline Female & $\begin{array}{l}655.0+9.6 \times \text { weight }(\mathrm{kg})+1.7 \times \text { height }(\mathrm{cm})- \\
4.7 \times \text { age }(\text { year })\end{array}$ \\
\hline \multicolumn{2}{|l|}{ Mifflin-St Jeor ${ }^{24}$} \\
\hline Male & $\begin{array}{l}9.99 \times \text { weight }(\mathrm{kg})+6.25 \times \text { height }(\mathrm{cm})-4.92 \times \\
\text { age }(\text { year })+5.00\end{array}$ \\
\hline Female & $\begin{array}{l}9.99 \times \text { weight }(\mathrm{kg})+6.25 \times \text { height }(\mathrm{cm})-4.92 \times \\
\text { age }(\text { year })-161.00\end{array}$ \\
\hline \multicolumn{2}{|l|}{ FAO/WHO/UNU 25} \\
\hline \multicolumn{2}{|l|}{ Male, age (years) } \\
\hline $18-30$ & $15.4 \times$ weight $(\mathrm{kg})+27.0 \times$ height $(\mathrm{m})+717.0$ \\
\hline $31-60$ & $11.3 \times$ weight $(\mathrm{kg})+16.0 \times$ height $(\mathrm{m})+901.0$ \\
\hline$\geq 61$ & $8.8 \times$ weight $(\mathrm{kg})+1,128.0 \times$ height $(\mathrm{m})+1,071.0$ \\
\hline \multicolumn{2}{|l|}{ Female, age (years) } \\
\hline $18-30$ & $13.3 \times$ weight $(\mathrm{kg})+334.0 \times$ height $(\mathrm{m})+35.0$ \\
\hline $31-60$ & $8.7 \times$ weight $(\mathrm{kg})+25.0 \times$ height $(\mathrm{m})+865.0$ \\
\hline$\geq 61$ & $9.2 \times$ weight $(\mathrm{kg})+637.0 \times$ height $(\mathrm{m})+302.0$ \\
\hline \multicolumn{2}{|l|}{ Schofield ${ }^{26}$} \\
\hline \multicolumn{2}{|l|}{ Male, age (years) } \\
\hline $18-30$ & I5.I $\times$ weight $(\mathrm{kg})+692.0$ \\
\hline $31-60$ & II. $5 \times$ weight $(\mathrm{kg})+873.0$ \\
\hline$\geq 61$ & $11.7 \times$ weight $(\mathrm{kg})+588.0$ \\
\hline \multicolumn{2}{|l|}{ Female, age (years) } \\
\hline $18-30$ & I $4.8 \times$ weight $(\mathrm{kg})+487.0$ \\
\hline $31-60$ & $8.1 \times$ weight $(\mathrm{kg})+846.0$ \\
\hline$\geq 61$ & $9.1 \times$ weight $(\mathrm{kg})+659.0$ \\
\hline
\end{tabular}

Abbreviation: $\mathrm{FAO} / \mathrm{WHO} / \mathrm{UNU}$, Food and Agriculture Organization/World Health Organization/United Nations University. 


\section{Statistical analysis}

Descriptive statistical analyses were performed to describe the demographic and clinical variables. To compare the main demographic and clinical characteristics between sexes, an unpaired Student's $t$-test was performed to analyze continuous variables. The data are presented as the means \pm standard deviation. The relationship between measured and predicted REEs was tested using simple linear regression analysis. The root mean square error (RMSE) was used to evaluate the model fit. Pearson's correlation coefficient $(r)$ was calculated to observe the association between the measured and predicted REEs for each of the predictive regression equations used. Bland-Altman analysis ${ }^{27}$ was used to calculate agreement between the measured and predicted REEs. A value of $P<0.05$ was considered significant. Data were analyzed using the PASW Statistics 18 software for Windows (IBM Corporation, Armonk, NY, USA).

\section{Results}

\section{Participant characteristics}

The characteristics of the participants are listed in Table 2. Significant differences were found between sexes in the anthropometric measurements, such as body weight and height. Moreover, males had significantly higher measured and predicted REEs than females. No differences were observed for any of the other characteristics.

\section{Linear regression}

In all participants, linear regression analysis revealed that the Harris-Benedict equation had the lowest RMSE and thus the best predictive accuracy of all tested equations ( $\mathrm{RMSE}=283.41$, $r=0.617, P<0.001$ ), followed by the Mifflin-St Jeor equation (RMSE $=291.31, r=0.588, P<0.001$ ), the Schofield equation $(\mathrm{RMSE}=301.70, r=0.546, P<0.001)$, and the $\mathrm{FAO} /$
WHO/UNU equation $(\mathrm{RMSE}=303.93, r=0.536, P<0.001)$. All four predictive equations were found to reliably predict the measured REE $(P<0.001)$.

In males, linear regression analysis revealed that the Harris-Benedict equation had the lowest RMSE and thus the best predictive accuracy of all tested equations $(\mathrm{RMSE}=319.04, r=0.613, P<0.001$ ), followed by the Mifflin-St Jeor equation (RMSE $=322.38, r=0.602$, $P<0.001$ ), the Schofield equation (RMSE $=339.86$, $r=0.540, P<0.001)$, and the $\mathrm{FAO} / \mathrm{WHO} / \mathrm{UNU}$ equation (RMSE $=345.77, r=0.516, P<0.001)$. All four predictive equations were found to reliably predict the measured REE in males $(P<0.001)$.

In females, linear regression analysis revealed that the Mifflin-St Jeor equation had the lowest RMSE and thus the best predictive accuracy of all tested equations (RMSE $=229.66$, $r=0.593, P<0.001$ ), followed by the $\mathrm{FAO} / \mathrm{WHO} / \mathrm{UNU}$ equation $(\mathrm{RMSE}=231.52, r=0.584, P<0.001$ ), the Harris-Benedict equation (RMSE $=232.56, r=0.579, P<0.001$ ), and the Schofield equation $(\mathrm{RMSE}=238.41, r=0.549, P<0.001)$. All four predictive equations were found to reliably predict the measured REE in females $(P<0.001)$.

\section{Bland-Altman analysis}

For all participants, Bland-Altman analysis revealed that the Harris-Benedict $(-1.7 \pm 282.3 \mathrm{kcal} /$ day; Figure 1) and Mifflin-St Jeor ( $-46.7 \pm 290.3 \mathrm{kcal} /$ day; Figure 2$)$ equations did not show a significant bias in the prediction of REE. For the other two equations, Bland-Altman analysis showed significant mean biases of $88.7 \pm 305.5 \mathrm{kcal} /$ day for the $\mathrm{FAO} /$ WHO/UNU equation (Figure 3 ) and $64.7 \pm 301.8 \mathrm{kcal} /$ day for the Schofield equation (Figure 4).

In males, Bland-Altman analysis revealed that the Harris-Benedict $(27.6 \pm 316.4 \mathrm{kcal} /$ day $)$ and Mifflin-

Table 2 Anthropometric characteristics and resting energy expenditures (REEs) of subjects

\begin{tabular}{|c|c|c|c|c|}
\hline Variable & Total $(n=\mid 10)$ & Male $(n=6 I)$ & Female $(n=49)$ & $P$-value ${ }^{a}$ \\
\hline Age (years) & $45.9 \pm 13.2$ & $46.8 \pm 13.1$ & $44.8 \pm 13.4$ & 0.440 \\
\hline Height (cm) & $164.1 \pm 8.4$ & $168.4 \pm 7.1$ & $158.8 \pm 6.8$ & $<0.001$ \\
\hline Weight $(k g)$ & $66.5 \pm 13.1$ & $68.9 \pm 13.1$ & $63.5 \pm 12.6$ & 0.029 \\
\hline Body mass index $\left(\mathrm{kg} / \mathrm{m}^{2}\right)$ & $24.7 \pm 4.5$ & $24.2 \pm 4.0$ & $25.2 \pm 5.1$ & 0.263 \\
\hline REE measured (kcal/day) & $1,442 \pm 358$ & $1,506 \pm 400$ & $1,362 \pm 282$ & 0.029 \\
\hline REE Harris-Benedict ${ }^{23}$ (kcal/day) & $1,440 \pm 230$ & $1,534 \pm 246$ & $1,323 \pm 143$ & $<0.001$ \\
\hline REE Mifflin-St Jeor ${ }^{24}$ (kcal/day) & $1,395 \pm 224$ & $1,515 \pm 192$ & $1,245 \pm 162$ & $<0.001$ \\
\hline REE FAO/WHO/UNU ${ }^{25}$ (kcal/day) & $1,530 \pm 235$ & $\mathrm{I}, 656 \pm 227$ & $1,375 \pm 127$ & $<0.001$ \\
\hline REE Schofield ${ }^{26}$ (kcal/day) & $1,506 \pm 226$ & $1,625 \pm 218$ & $1,359 \pm 127$ & $<0.001$ \\
\hline
\end{tabular}

Notes: ${ }^{V}$ alues are the mean \pm standard deviation. Student's unpaired $t$-test was performed to compare sex differences. Abbreviation: FAO/WHO/UNU, Food and Agriculture Organization/World Health Organization/United Nations University. 


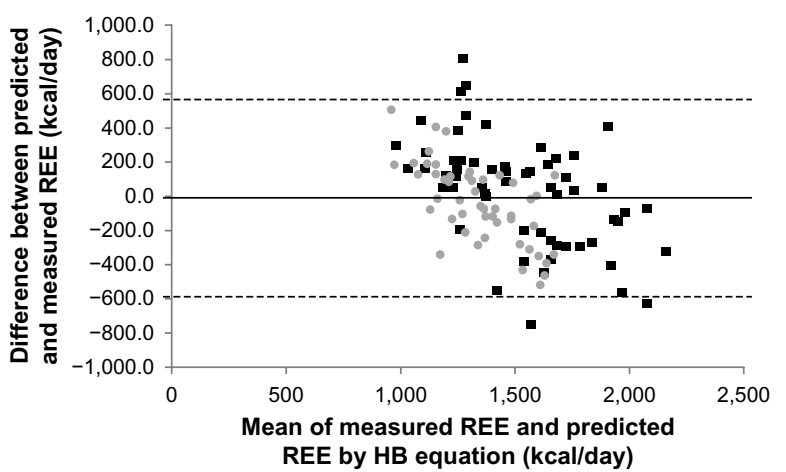

Figure I Bland-Altman plot of measured resting energy expenditure (REE) and predicted REE using the Harris-Benedict $(\mathrm{HB})$ equation ${ }^{23}$ in males (black squares) and females (gray circles).

Note: The solid line represents the mean bias, and the dashed lines represent the limits of agreement (mean \pm two standard deviations).

St Jeor $(9.4 \pm 323.3 \mathrm{kcal} /$ day $)$ equations did not show a significant bias in the prediction of REE. For the other two equations, the analysis showed significant mean biases of $149.5 \pm 343.5 \mathrm{kcal} /$ day for the $\mathrm{FAO} / \mathrm{WHO} / \mathrm{UNU}$ equation and $119.0 \pm 337.0 \mathrm{kcal} /$ day for the Schofield equation.

In females, Bland-Altman analysis revealed that the Harris-Benedict $(-38.1 \pm 231.1 \mathrm{kcal} /$ day $), \mathrm{FAO} / \mathrm{WHO} / \mathrm{UNU}$ $(13.1 \pm 232.2 \mathrm{kcal} / \mathrm{day})$, and Schofield $(-2.9 \pm 237.6 \mathrm{kcal} / \mathrm{day})$ equations did not show a significant bias in the prediction of REE. In contrast, the analysis showed a significant mean bias of $-116.5 \pm 227.3 \mathrm{kcal} /$ day for the Mifflin-St Jeor equation.

\section{Discussion}

To the best of our knowledge, this study is the first to compare actual REE measurements with predicted REEs determined by the Harris-Benedict, Mifflin-St Jeor, FAO/WHO/UNU, and Schofield equations in Asian patients diagnosed with schizophrenia. REE corresponds to the calories the body uses to maintain vital body functions (eg, heart rate, brain function, and

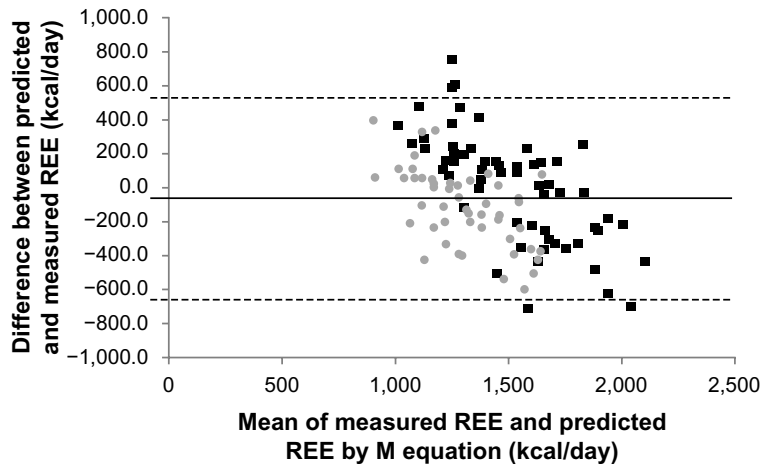

Figure 2 Bland-Altman plot of measured resting energy expenditure (REE) and predicted REE using the Mifflin-St Jeor (M) equation ${ }^{24}$ in males (black squares) and females (gray circles).

Note: The solid line represents the mean bias, and the dashed lines represent the limits of agreement (mean \pm two standard deviations).

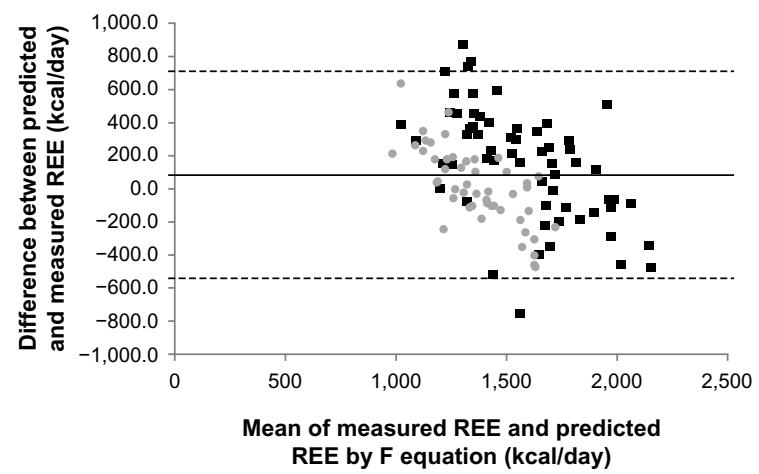

Figure 3 Bland-Altman plot of measured resting energy expenditure (REE) and predicted REE using the Food and Agriculture Organization/World Health Organization/United Nations University (F) equation ${ }^{25}$ in males (black squares) and females (gray circles). Note: The solid line represents the mean bias, and the dashed lines represent the limits of agreement (mean \pm two standard deviations).

breathing) and represents the number of calories an individual would burn daily if awake at rest. An FAO/WHO/UNU expert panel adopted the principle of expressing the energy requirements of adults in terms of multiples of REE. ${ }^{25}$ Therefore, REE is used to estimate the 24-hour EE and physical activity level (24-hour EE divided by REE). In this study, we found that in Japanese patients with schizophrenia, the Harris-Benedict equation reliably predicted the energy needs of male and female patients with an insignificant estimation bias.

Individuals with a lower REE tend to gain more weight than those with a normal REE. ${ }^{28,29}$ To develop an appropriate intervention program for weight reduction in patients with schizophrenia, an accurate assessment of REE for each patient is needed. ${ }^{28}$

Recently, direct or indirect calorimeters and respiratory chambers have been developed to measure REE. However, these devices are expensive, and their operation requires trained personnel and long testing times for patients with schizophrenia. Therefore, the calculation of REE by

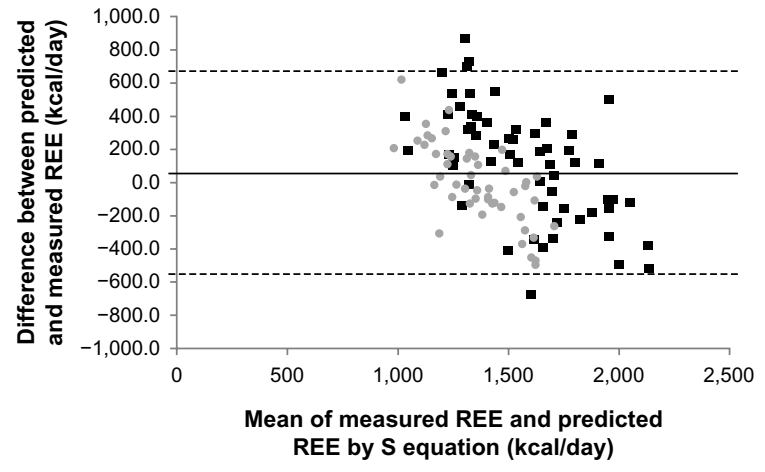

Figure 4 Bland-Altman plot of measured resting energy expenditure (REE) and predicted REE using the Schofield (S) equation ${ }^{26}$ in males (black squares) and females (gray circles).

Note: The solid line represents the mean bias, and the dashed lines represent the limits of agreement (mean \pm two standard deviations). 
mathematical equation has been adopted as the major method to assess the energy needs of individuals. ${ }^{28}$

In the study reported here, we employed four predictive equations for REE. These equations were developed to predict the REE in healthy populations. The Harris-Benedict equation was derived from predominantly normal-weight Caucasian males $(n=136)$ aged 16 to $63(27 \pm 9)$ years and females $(n=103)$ aged 15 to $74(31 \pm 14)$ years in studies conducted from approximately 1907 to $1917 .{ }^{23}$ The Mifflin-St Jeor equation was developed from a sample of 498 normal-weight, overweight, obese, and severely obese individuals aged 19 to 78 (44.5 \pm 14.1 ) years. ${ }^{24}$ The racial composition of the sample was not specified, and the representation of older adults (75 to 84 years) was limited. Finally, the FAO/WHO/UNU and Schofield equations were developed from a database of the scientific literature published from 1914 to $1980 .{ }^{25,26}$ This database consisted of 7,173 subjects, mostly derived from European military and police recruits. The age of the study participants ranged from 19 to 82 years.

A few studies have compared the measured and predicted REEs of SMI patients in Western populations. A previous study of eight Australian male patients with schizophrenia demonstrated that the Harris-Benedict equation overestimated the REE by $284 \mathrm{kcal} /$ day. ${ }^{19}$ These researchers also found that the Schofield equation overestimated the REE by $287 \mathrm{kcal} /$ day. In another study in Greece, ${ }^{21}$ the MifflinSt Jeor equation was determined to be the most appropriate equation for 128 male and female patients with mood or psychotic disorders. Moreover, in our study, this equation was found to be the most accurate because it produced estimation errors of only $-1.7 \mathrm{kcal} /$ day in all participants. In Skouroliakou et al's study, ${ }^{21}$ the predictive Harris-Benedict and Schofield equations were found to greatly overestimate the real energy needs of male and female patients with SMIs. For example, in males, the Harris-Benedict equation overestimated the measured REE by $175 \mathrm{kcal} /$ day. In a study of 15 patients with bipolar disorder in Italy, ${ }^{20}$ researchers found that the Harris-Benedict equation overestimated REE by $483 \mathrm{kcal} /$ day and that the Schofield equation overestimated REE by $397 \mathrm{kcal} /$ day.

Our results show sex differences in agreement between the measured and predicted REEs for predictive equations. Because the predictive equations were developed mainly from measurements made on Caucasian subjects, ethnicity could explain the observed differences. In addition, sex hormones such as estrogens and progesterone can affect REE, ${ }^{29}$ and menstrual condition or menopause may have affected our results.
In contrast to previous studies, our results show that the Harris-Benedict equation was not biased in the prediction of REE. One possible explanation for this is that the mean body mass index of the participants in this study was lower than that of the studies from Western countries. Obesity might be related to a hypometabolic state that is reflected as a decreased REE/kg body mass. ${ }^{30}$ Another explanation is that differences in physical exercise, sleep pattern, illness duration, severity of negative symptoms, body composition, ethnicity, and socio-environmental factors might have affected our findings. ${ }^{31-34}$ In particular, antipsychotic medications may be an important factor. Although some studies have found unaltered REEs between patients who were taking antipsychotics and those who were not, ${ }^{5,35}$ the use of first- or second-generation antipsychotics might have confounded the results. However, a lack of research concerning these mentioned factors in this population limits our ability to determine those factors that might have contributed to the differences among studies. Additional studies are necessary to further establish the predictive value of these equations in a larger population taking different antipsychotic drugs.

\section{Conclusion}

The findings of this study suggest the use of the HarrisBenedict equation as the most appropriate means of estimating the REE of male and female patients with schizophrenia taking antipsychotics. An equation that can predict the energy needs of patients with schizophrenia that has a low estimation error and low cost might be useful for a weight reduction program for these patients.

\section{Acknowledgments}

The authors would like to thank all coworkers for their skillful contributions to the data collection and management. Funding for this study was provided by a Grant-in-Aid for Young Scientists (B); The Ministry of Education, Culture, Sports, Science and Technology, Japan; the Karoji Memorial Fund for Medical Research (Grant B); and SENSHIN Medical Research Foundation.

\section{Disclosure}

The authors declare that they have no competing interests in this work.

\section{References}

1. Susce MT, Villanueva N, Diaz FJ, de Leon J. Obesity and associated complications in patients with severe mental illnesses: a cross-sectional survey. J Clin Psychiatry. 2005;66(2):167-173. 
2. Dickerson FB, Brown CH, Kreyenbuhl JA, et al. Obesity among individuals with serious mental illness. Acta Psychiatr Scand. 2006;113(4): 306-313.

3. Sugawara N, Yasui-Furukori N, Sato Y, et al. Prevalence of metabolic syndrome among patients with schizophrenia in Japan. Schizophr Res. 2010;123(2-3):244-250.

4. Bobes J, Rejas J, Garcia-Garcia M, et al; EIRE Study Group. Weight gain in patients with schizophrenia treated with risperidone, olanzapine, quetiapine or haloperidol: results of the EIRE study. Schizophr Res. 2003;62(1-2):77-88.

5. Gothelf D, Falk B, Singer P, et al. Weight gain associated with increased food intake and low habitual activity levels in male adolescent schizophrenic inpatients treated with olanzapine. Am J Psychiatry. 2002;159(6):1055-1057.

6. Vancampfort D, Knapen J, Probst M, Scheewe T, Remans S, De Hert M. A systematic review of correlates of physical activity in patients with schizophrenia. Acta Psychiatr Scand. 2012;125(5):352-362.

7. Martin RL, Cloninger CR, Guze SB, Clayton PJ. Mortality in a follow-up of 500 psychiatric outpatients. I. Total mortality. Arch Gen Psychiatry. 1985;42(1):47-54.

8. Allebeck P. Schizophrenia: a life-shortening disease. Schizophr Bull. 1989;15(1):81-89.

9. Leucht S, Burkard T, Henderson J, Maj M, Sartorius N. Physical illness and schizophrenia: a review of the literature. Acta Psychiatr Scand. 2007;116(5):317-333.

10. Chwastiak LA, Rosenheck RA, McEvoy JP, et al. The impact of obesity on health care costs among persons with schizophrenia. Gen Hosp Psychiatry. 2009;31(1):1-7.

11. Weiden PJ, Mackell JA, McDonnell DD. Obesity as a risk factor for antipsychotic noncompliance. Schizophr Res. 2004;66(1):51-57.

12. De Hert M, Peuskens B, van Winkel R, et al. Body weight and self-esteem in patients with schizophrenia evaluated with B-WISE. Schizophr Res. 2006;88(1-3):222-226.

13. Sugawara N, Yasui-Furukori N, Sato Y, et al. Body mass index and quality of life among outpatients with schizophrenia in Japan. BMC Psychiatry. 2013;13:108.

14. Goran MI. Energy metabolism and obesity. Med Clin North Am. 2000;84(2):347-362.

15. Vaughan L, Zurlo F, Ravussin E. Aging and energy expenditure. Am J Clin Nutr. 1991;53(4):821-825.

16. Ferraro R, Lillioja S, Fontvieille AM, Rising R, Bogardus C, Ravussin E. Lower sedentary metabolic rate in women compared with men. J Clin Invest. 1992;90(3):780-784.

17. Illner K, Brinkmann G, Heller M, Bosy-Westphal A, Müller MJ. Metabolically active components of fat free mass and resting energy expenditure in nonobese adults. Am J Physiol Endocrinol Metab. 2000;278(2):E308-E315.

18. Rosenbaum M, Leibel RL, Hirsch J. Obesity. N Engl J Med. 1997; 337(6):396-407.

19. Sharpe JK, Byrne NM, Stedman TJ, Hills AP. Resting energy expenditure is lower than predicted in people taking atypical antipsychotic medication. J Am Diet Assoc. 2005;105(4):612-615.
20. Soreca I, Mauri M, Castrogiovanni S, Simoncini M, Cassano GB. Measured and expected resting energy expenditure in patients with bipolar disorder on maintenance treatment. Bipolar Disord. 2007;9(7):784-788.

21. Skouroliakou M, Giannopoulou I, Kostara C, Vasilopoulou M. Comparison of predictive equations for resting metabolic rate in obese psychiatric patients taking olanzapine. Nutrition. 2009;25:188-193.

22. American Psychiatric Association (APA). Diagnostic and Statistical Manual of Mental Disorders. 4th ed. Washington DC: APA; 1994.

23. Harris JA, Benedict FG. A Biometric Study of Human Basal Metabolism. Proc Natl Acad Sci U S A. 1918;4(12):370-373.

24. Mifflin MD, St Jeor ST, Hill LA, Scott BJ, Daugherty SA, Koh YO. A new predictive equation for resting energy expenditure in healthy individuals. Am J Clin Nutr. 1990;51(2):241-247.

25. Energy and protein requirements. Report of a joint FAO/WHO/UNU Expert Consultation. World Health Organ Tech Rep Ser. 1985;724: 1-206.

26. Schofield WN. Predicting basal metabolic rate, new standards and review of previous work. Hum Nutr Clin Nutr. 1985;39 Suppl 1:5-41.

27. Bland JM, Altman DG. Statistical methods for assessing agreement between two methods of clinical measurement. Lancet. 1986;327(8476): 307-310.

28. Frankenfield D, Roth-Yousey L, Compher C. Comparison of predictive equations for resting metabolic rate in healthy nonobese and obese adults: a systematic review. J Am Diet Assoc. 2005;105(5):775-789.

29. Day DS, Gozansky WS, Van Pelt RE, Schwartz RS, Kohrt WM. Sex hormone suppression reduces resting energy expenditure and \{beta $\}$ adrenergic support of resting energy expenditure. J Clin Endocrinol Metab. 2005;90(6):3312-3317.

30. Cuerda C, Merchan-Naranjo J, Velasco C, et al. Influence of resting energy expenditure on weight gain in adolescents taking secondgeneration antipsychotics. Clin Nutr. 2011;30(5):616-623.

31. Carotenuto M, Bruni O, Santoro N, Del Giudice EM, Perrone L, Pascotto A. Waist circumference predicts the occurrence of sleep-disordered breathing in obese children and adolescents: a questionnaire-based study. Sleep Med. 2006;7(4):357-361.

32. Esposito M, Antinolfi L, Gallai B, et al. Executive dysfunction in children affected by obstructive sleep apnea syndrome: an observational study. Neuropsychiatr Dis Treat. 2013;9:1087-1094.

33. Carotenuto M, Esposito M, Parisi L, et al. Depressive symptoms and childhood sleep apnea syndrome. Neuropsychiatr Dis Treat. 2012;8: 369-373.

34. Battaglia G, Alesi M, Inguglia M, et al. Soccer practice as an add-on treatment in the management of individuals with a diagnosis of schizophrenia. Neuropsychiatr Dis Treat. 2013;9:595-603.

35. Nilsson BM, Forslund AH, Olsson RM, Hambraeus L, Wiesel FA. Differences in resting energy expenditure and body composition between patients with schizophrenia and healthy controls. Acta Psychiatr Scand. 2006;114(1):27-35.
Neuropsychiatric Disease and Treatment

\section{Publish your work in this journal}

Neuropsychiatric Disease and Treatment is an international, peerreviewed journal of clinical therapeutics and pharmacology focusing on concise rapid reporting of clinical or pre-clinical studies on a range of neuropsychiatric and neurological disorders. This journal is indexed on PubMed Central, the 'PsycINFO' database and CAS.
Dovepress

The manuscript management system is completely online and includes a very quick and fair peer-review system, which is all easy to use. Visit http://www.dovepress.com/testimonials.php to read real quotes from published authors. 